Юлия Юрченко

Университет Экс-Марсель

Факультет искусств, словесности, языков

и гуманитарных наук

Отделение славянских исследований

yulia.yurchenko@hotmail.com
УДК 811.161 .1 '38

https://doi.org/10.18485/slavistika.2018.22.2.5

оригинални научни рад

примљено 14.07.2018.

прихваћено за штампу 04.10.2018.

\title{
ИЗУЧЕНИЕ ЯЗЫКОВЫХ СТЕРЕОТИПОВ НА МАТЕРИАЛЕ СОВРЕМЕННОГО РОССИЙСКОГО ПОЛИТИЧЕСКОГО ДИСКУРСА
}

В статье освещаются некоторые исследовательские подходы к осмыслению природы стереотипа. Понятие стереотип рассматривается в ключе семантической концепции, которую в разное время разрабатывали Х. Патнэм, Б. Фраден, Ж.-Кл. Анскомбр. Исследуется содержание единиц языкового выражения, распределение компонентов семантики слова, а также круг вопросов, относящихся к сочетаемости языковых единиц. Особенности взаимодействия слов в рамках словосочетаний, зависящие от характера семантических признаков данных языковых единиц, показаны на примерах из текстов современной российской политической речи. Значительное место в статье отводится теме переноса значения и роли стереотипа в образовании метафоры. Анализируется возможность использования стереотипных характеристик слова как части лингвистической аргументативной стратегии, в рамках которой в политическом дискурсе сознательно воспроизводятся концепты и представления, обеспечивающие персуазивность коммуникации.

Ключевые слова: семантика, стереотип, коннотация, воспроизводимость, комбинаторика, метафора, политический дискурс, персуазивность.

The article discusses various research approaches towards understanding the nature of stereotype, further considered through the lens of semantic concepts developed by H. Putnam, B. Fradin, and J.-Cl. Anscombre. We closely examine the content of linguistic items, the distribution of the semantic components of words, and a number of issues related to combinatorics. Based on examples from modern Russian political speeches, we illustrate the idea that the process of uniting language elements within word combinations depends on the nature of semantic features of such language elements. Then the transfer of meaning and the role of stereotype in metaphor formation are discussed. Finally, we analyze the possibility of using stereotypical characteristics of words as a part of a linguistic argument strategy that implies the deliberate use of concepts and ideas with the purpose of providing persuasive communication in political discourse.

Key words: semantics, stereotype, connotation, repeatability, combinatorics, metaphor, political discourse, persuasiveness.

\section{Исследование политической речи в российской лингвистике}

За последние двадцать пять лет лингвистическое исследование языка политики развернулось в российском языкознании как перспективное направление: изучаются и фиксируются не только механизмы и признаки, свойственные политической речи в целом, но и процессы изменений, непрерывно происходящие в сознании лингвокультурного сообщества и отражающиеся в языке политики за сравнительно короткие отрезки времени. Активное изучение в России коммуникативных приёмов, стратегий и тактик, реализуемых через политический дискурс, обусловлено целым рядом факторов: это и глобальные общественноисторические преобразования последних десятилетий, и стремительный рост

Славистика XXII/2 (2018) 
информационно-коммуникационных технологий, и формирование единого информационного пространства. Для российской лингвистики знаковым был выпуск в 1994 году «Словаря русских политических метафор», разработанного в Москве А.Н. Барановым и Ю.Н. Карауловым. Исследования политического дискурса в разрезе семиотики проводятся Е.И. Шейгал и её последователями в Москве, один же из наиболее активных российских научных центров, занимающийся, в частности, методологическими и практическими разработками в области политической метафоры, находится в Екатеринбурге и концентрируется вокруг исследований А.П. Чудинова и Э.В. Будаева ${ }^{1}$.

При исследовании политических стратегий и тактик язык осознаётся лингвистами как основной инструмент достижения цели политическим субъектом. Стереотип же рассматривается как часть лингвистической аргументативной стратегии, в рамках которой в политическом дискурсе сознательно воспроизводятся концепты и представления, обеспечивающие персуазивность коммуникации ${ }^{2}$. Лингво-ментальные стереотипы, при этом, трактуются как «особые мыслительные структуры, которые сохраняются в сознании с помощью языкового знака» (Чернявская 2006: 53).

\section{В какой сфере находится стереотип?}

Нередко в обиходной речи можно услышать сочетания: «мыслить стереотипами», «ломать шаблоны»; «шаблонно воспринимать», «схематично интерпретировать [слово, означающее лицо, предмет, явление, действие, состояние]»; «говорить стереотипными фразами». Эти высказывания, на наш взгляд, удачно отражают суть трёх основных подходов к осмыслению стереотипа:

(1) стереотип как схематичное стандартное представление о предмете, лежащее во внеязыковой сфере, «преконструкт» в терминологии французских философов М. Пешё и П. Анри;

(2) стереотип в семантической концепции, разработанной X. Патнэмом $(1985,1990)$ и получившей развитие - в частности, во Франции - в работах Б. Фрадена, Ж.-М. Марандена, О. Дюкро, в «теории семантических стереотипов» Ж.-Кл. Анскомбра, в разработке Дж. Клейбером понятий «ассоциативная анафора» и «прототип»;

${ }^{1}$ Помимо перечисленных российских специалистов, вопросы политического языка разрабатывали В.И. Карасик, В.Г. Костомаров, Л.П. Крысин, О.П. Ермакова, Е.А. Земская, Е.Г. Казакевич, Н.А. Купина, П.Б. Паршин, Г.Г. Почепцов, Л.И. Скворцов, В.Н. Шапошников, В.И. Шаховский и другие лингвисты. Лексико-фразеологические инновации в современном политическом дискурсе были проанализированы в публикациях О.И. Воробьевой, Е.А. Земской, Н.В. Черниковой и др.

2 Персуазивность рассматривается как потенциальный прагматический смысл языковых единиц и не сводится исключительно к классическим риторическим приёмам и средствам образности. Под персуазивностью подразумевается воздействие на реципиента через текст в широком смысле. Лингвистические явления различных уровней (лексического, грамматического, стилистического), обладающие сильным воздействующим потенциалом, способны выдвигать связанные с ними смыслы в центр внимания.

${ }^{3}$ Согласно концепции Ж. Клейбера, изложенной в работе «Ассоциативная анафора», единица языка и её «референт» находятся между собой в анафорических отношениях. Клейбер утверждает, что анафорическим является такое выражение, которое отсылает к 
(3) стереотип как воспроизводимая языковая формула: в этом ключе лингвисты (Д.О. Добровольский, Ш. Шапира) изучают устойчивые словосочетания, идиоматические выражения, пословицы, поговорки, формулы вежливости, рутинные фразы, слоганы.

Все три концепции охватывают как понятийную сферу, так и область формы, то есть материального языкового выражения. Однако нам представляется, что исследования в рамках указанных научных подходов идут, в некотором смысле, в противоположных направлениях: (а) от понятийного ядра, некоего абстрактного представления о предмете к набору его материальных языковых выражений; (б) от языкового знака к выявлению его стереотипных значений (интенсионала, «стереотипных фраз», коннотаций). Иначе говоря, исследователи дискурса, для которых стереотип это устойчивый, упрощённый, эмоционально окрашенный ментальный образ, движутся от заданного ментального стандартизированного способа концептуализации действительности к языковым воплощениям изучаемого образа или представления о предмете. Тогда как при семасиологическом подходе стереотип является, скорее, инструментом исследования. У единицы языкового материала определяется список стереотипных признаков (или «открытый список стереотипных фраз», в терминологии Фрадена), которые приписываются данной единице в определённом социокультурном контексте; таким образом, исследуется содержание определённой единицы языкового выражения, а также широкий круг вопросов, относящихся к её комбинаторике, образованию фразем и других устойчивых языковых единств.

В российской лингвистике хорошо известны семантические теории стереотипа Х. Патнэма, Ж.-Кл. Анскомбра, Е. Бартминьского; к проблеме стереотипа в России обращались Л.П. Крысин, Е.Л. Березович, О.В. Белова, В.А. Плунгян, Е.В. Рахилина, И.М. Кобозева и другие. Языковеды разрабатывают вопросы соотношения понятий «топос», «клише», «штамп», «стереотип»; исследуют зависимость метафорических образований от стереотипных признаков слова, часть значения которого подвергается метафорическому переосмыслению; выявляют связь между коннотацией и стереотипом; группируют стереотипы по семантическим полям и эмоционально-оценочным характеристикам; исследуют устойчивость и воспроизводимость стереотипов и т. д. Значительное количество вопросов, связанных со стереотипами, получает рассмотрение в области этнолингвистики. Исследователи, работающие в русле этнолингвистики и политической лингвистики, утверждают, что стереотипы обязаны своим возникновением двум особенностям человеческого сознания: стремлению к конкретизации, то есть связыванию абстрактных представлений с конкретными образами, и тенденции к упрощению, то есть к выделению нескольких признаков в качестве ведущих для обозначения сложных явлений (Чудинов 2008: 46).

Е. Бартминьский, обратившийся к изучению стереотипа в рамках этнолингвистики, отмечает, что «процессы стереотипизации охватывают мышление и высказывания о людях, а также о предметах и событиях» (Бартминьский 2009: 12). Как и французские лингвисты, Е. Бартминьский опирается на семанти-

явлению, уже известному слушателю, присутствующему в его непосредственной памяти, текстуальной или ситуационной (Kleiber 2001: 29).

Славистика XXII/2 (2018) 
ческую концепцию стереотипа Х. Патнэма и говорит об элементарных стереотипных суждениях, неосознанно приписываемых всем объектам класса, объединяемого с помощью определённой языковой единицы (Бартминьский 2005). «Центральной частью содержания стереотипов являются описательные признаки (познавательные), иногда маргинальные и несущественные, но субъективно возводимые в ранг типических; описательному содержанию сопутствует интеллектуальная и эмоциональная оценка» (Бартминьский 2009: 15). Среди функций семантических стереотипов Е. Бартминьский выделяет репрезентацию культуры и социальную оценку действительности, стабилизацию картины мира и программирование поведения в рамках лингвокультурного сообщества.

От семантического стереотипа к стереотипным семантико-синтаксическим фигурам речи

Процесс объединения языковых элементов в устойчивые языковые сращения безусловно зависит от характера семантических признаков данных языковых элементов (Beliakov 2012; Schapira 2014). Предлагаем рассмотреть этот процесс на примере лексемы базар. Общие усреднённые представления носителей русского языка о понятии, выражаемом словом базар, зафиксированы в наборе стереотипных признаков или «стереотипных фраз», приписываемых языковой единице базар. Классифицирующая словарная дефиниция данной лексемы согласно толковому словарю С.И. Ожегова - «место для торговли, обычно на площади, а также розничная торговля на таком месте». Однако в лингвокультурном сознании также бытует представление о базаре как о месте беспорядочной, нерегламентированной, не всегда честной торговли, о сборище развязных, крикливых людей, неблагонадёжных социальных элементов. Благодаря популяризации криминального арго 4 носитель русского языка также может подразумевать под словом базар шумную, напористую речь или же совокупность изречений и заявлений некоего лица. Подобные стереотипные признаки, приписываемые лексеме базар, позволяют без труда понять смысл предложения Одно дело - законы рынка, совсем другое - понятия базара, а также значение словосочетания дикий воровской базар. Данное словосочетание было зафиксировано в текстах, составленных представителями КПРФ и содержащих оценку определённых аспектов функционирования официальной власти в России. При актуализации стереотипных признаков слова базар, содержащих отрицательную оценку, словосочетания *красивый базар и *порядочный базар представились бы нелогичными. Однако если бы слово базар было употреблено в своём основном денотативном значении, предложение $\mathrm{Ha}$ городской площади был открыт нарядный праздничный базар не вызвало бы нареканий. В этом случае речь шла бы о денотативных признаках лексемы, зафиксированных в словаре: «место для розничной торговли» или «торговля на открытых площадях».

${ }^{4}$ Исследовали отмечают, что для языка российской политики последних лет стали характерными, среди прочих, два явления: «интенсификация процессов заимствования иностранных слов и значительное влияние жаргонной и просторечной языковой среды» (Чудинов 2008: 24). 
Эмпирические наблюдения за языком политической речи подтверждают истинность сведений, почерпнутых при изучении научной литературы по теме лингвистического стереотипа:

- комбинаторность лексических единиц на семантическом уровне обусловлена, среди других факторов, набором наивных, обывательских стереотипных представлений о предмете;

- при образовании воспроизводимых словосочетаний с ярким оценочным компонентом актуализируются стереотипные признаки обозначаемого, закреплённые скорее в обыденном сознании говорящего, чем в фонде энциклопедических знаний.

Наша гипотеза заключается в том, что стереотипные признаки лексемы бaзар, проявленные и зафиксированные в выражении дикий воровской базар, транслируются на словосочетание официальная власть, постепенно включаясь в список стереотипных фраз, при помощи которых это словосочетание репрезентируется в сознании адресной аудитории политических групп, оппозиционных существующей власти.

Когда в языке политики систематически используются устойчивые языковые выражения, речевые клише, в которых актуализируются определённые стереотипные признаки составных элементов, адресат перестаёт воспринимать их критически. Денотативные и референциальные признаки единицы языка (лексемы, отдельных элементов устойчивого выражения или целого фразеологического единства) отходят на второй план, а на первый план выходят стереотипные характеристики слова. Носители языка перестают задумываться над содержанием словосочетаний, многократно произнесённых харизматичным политическим лидером и сотни раз повторённых по медиаканалам. Политическая речь наполняется определёнными паттернами, которые вызывают у реципиентов автоматическую реакцию, в некотором смысле блокируя рефлексию и критическое осмысление. П. Шародо, представитель французской школы дискурсанализа, в работе «Политический дискурс: маски власти» следующим образом описывает характер аргументации: политик должен «...предложить простое умозаключение, основанное на причинно-следственных связях, опираясь при этом на крепко укоренившиеся в обществе мнения [...] и подкрепить их посредством аргументов, которые должны произвести эффект доказательства» (Charaudeau 2005: 77) .

Если мы ознакомимся с текстами речей, произнесённых на заседаниях Генеральной Ассамблеи ООН Н. Хрущёвым и Ф. Кастро в 60-х годах прошлого века, а также просмотрим тексты выступлений нынешних политических лидеров Венесуэлы, мы сможем пронаблюдать, каким образом моделировалось коммунистическими партиями представление о внешней политике США. Речь Н. Хрущёва на 15-й Ассамблее ООН в 1960 году запомнилась в целом как эксцентричное событие, поскольку Первый секретарь ЦК КПСС не стесняясь высмеивал и демонизировал своих идеологических оппонентов. Так, в ходе за-

${ }^{5}$ «...proposer un raisonnement causal simple en s'appuyant sur des croyances fortes [...] et de les renforcer en apportant des arguments destinés à produire un effet de preuve » (Charaudeau 2005: 77).

Славистика XXII/2 (2018) 
седания Н. Хрущёв назвал филиппинского докладчика холуем американского империализма. Согласно толковому словарю Ожегова, слово холуй означает: (1) слуга, лакей (устар.), (2) раболепный приспешник, подхалим (перен., презр.) Мы предполагаем, что семантические процессы протекали следующим образом: в данном случае активирован не денотативный признак лексемы лакей - «слуга в господском доме», а оценочный стереотипный признак - «раболепный подхалим». Таким образом, через перенос описательной стереотипной характеристики $\mathrm{S}$, относящейся к лексеме $\mathrm{L}_{1}$ лакей, на имя $\mathrm{L}_{2}$ филиппинского докладчика, Хрущёв «прописал» оценочный стереотипный признак $\mathrm{S}$ лексемы $\mathrm{L}_{1}$ в область стереотипных признаков лексемы $\mathrm{L}_{2}$.

Обратимся теперь к случаям использования лексемы империалистический, с тем чтобы аналогичным образом проиллюстрировать развёртывание семантического процесса. Соединённые Штаты Америки характеризировались $\mathrm{H}$. Хрущёвым в негативном ключе как империалистическая держава. Если бы речь шла о принадлежности к Священной Римской империи, сторонниках Наполеона I или имперском стиле в архитектуре, можно было бы говорить о нейтральном референциальном значении лексемы $\mathrm{L}_{1}$ империалистический. Но в данном случае мы наблюдаем актуализацию оценочного стереотипного признака $\mathrm{S}$ «захватнический», «ведущий захватнические войны на территории других государств». По нашим предположениям, семантические процессы разворачиваются следующим образом: для лексемы $\mathrm{L}_{1}$ империалистический (имперский) автор текста определённым образом распределяет систему стереотипных признаков, помещая на первый план отрицательные оценочные признаки $\mathrm{S}$. В результате многократного повторения лексемы $\mathrm{L}_{1}$ империалистический $\mathrm{c}$ актуализированным оценочным стереотипным признаком $\mathrm{S}$, означенный признак $\mathrm{S}$ закрепляется за лексемой $\mathrm{L}_{1}$ в сознании адресата речи. Далее, при многократном повторении лексемы $\mathrm{L}_{1}$ империалистический с актуализированным стереотипным признаком $\mathrm{S}$ в отношении лексемы $\mathrm{L}_{2} C Ш A$, данный признак $\mathrm{S}$ прописывается в списке стереотипных признаков, относящихся к $\mathrm{L}_{2} C Ш А$.

В одном из фрагментов своего выступления Н. Хрущёв использует в качестве предиката к субъекту, выраженному $\mathrm{L}_{2}$ США, словосочетание самая империалистическая держава, возводя в превосходную степень оценочный стереотипный признак $\mathrm{S}$ лексемы $\mathrm{L}_{1}$ империалистический. Это способствует усилению и ускорению процесса закрепления отрицательного оценочного стереотипного признака $\mathrm{S}$ за лексемой $\mathrm{L}_{2} C W A$ в сознании адресата политической речи.

Следует упомянуть роль стереотипа в образовании метафоры. Политическая речь, стремясь удовлетворить своим целям - завоевать, перераспределить, легитимировать и удержать власть - оперирует стереотипными признаками слов, дабы связать понятия, зачастую мало связанные между собой. В процессе подобного ассоциативного сближения одну из главных ролей играет метафора ${ }^{6}$. В словарях может быть не зафиксировано переносное, метафорическое употребление той или иной лексемы, тогда как в политических текстах - через

${ }^{6}$ По определению Арутюновой, «метафора в ее наиболее очевидной форме - это транспозиция идентифицирующей (дескриптивной и семантически диффузной) лексики, предназначенной для указания на предмет речи, в сферу предикатов, предназначенных для указания на его признаки и свойства» (Арутюнова 1990: 19). 
актуализацию стереотипных семантических признаков - лексема получает активное хождение в качестве единицы метафорического переосмысления, усиливающей или ослабляющей положительные и отрицательные характеристики, приписываемые предмету на уровне целого лингвокультурного сообщества. Таким образом, подтверждается тезис о том, что языковые стереотипы и языковые клише заключают в себе общеизвестные «истины», информация о которых поступает к нам не из феноменологических сфер, а непосредственно из дискурca (Fournier Nguyen 2005: 40).

\section{Заключение}

В заключение этого краткого обзора наметим план и перспективы для более подробного исследования стереотипов в языке политики. Ввиду агональности политического дискурса представляется рациональным распределение корпусных данных на два блока: автостереотипы и гетеростереотипы. Очевидно, что разные политические и идеологические структуры могут находиться в состоянии борьбы, а могут сосуществовать на базе компромиссов. Таким образом, на основе исследования стереотипных признаков слов предлагается описать (1) способы языковой саморепрезентации политического движения, т.е. продемонстрировать языковые возможности формирования положительных представлений о cвoux/ingroup, и (2) способы семантической репрезентации политических противников, т.е. способы репрезентации других/outgroup как носителей иных представлений, ценностей, идеологий. Благодаря подобному исследованию корпусных данных можно определить, кто именно ходит под красным знаменем, кем являются жертвы системы и т. д.

На основе анализа языкового материала - синтаксических конструкций, примеров комбинаторики, языковых штампов, ко(н)текста - представляется возможным не только сформировать списки стереотипных признаков, относящихся к лицам и явлениям политического мира, но и установить шкалу значимости внутри этих списков, определив максимально проявленные, доминантные стереотипные признаки и менее проявленные, периферические признаки ${ }^{7}$. Стереотипные признаки при этом понимаются как открытый список потенциальных характеристик слов (Fradin 1984: 326), со временем способный изменяться даже в рамках одной политической идеологии.

В данном случае мы говорим об исследовании сознательного идеологического моделирования взглядов реципиентов посредством активации определённых стереотипных признаков языковых знаков. В этой связи реализуется функция социальной интеграции стереотипа, то есть функция поддержания внутренней спаянности сообщества через противопоставление другим сообществам ${ }^{8}$.

В том, что касается структуры языкового материала, нам представляется удачным типологически разделить исследование на (1) анализ семантических компонентов отдельных лексем, в том числе их оценочной и эмотивной составляющих, и (2) анализ словосочетаний и фразем как структур с большей или

7 Лингвистические тесты для выявления стереотипных и коннотативных признаков можно найти в работах И.А. Мельчука, Л.Н. Иорданской (Иорданская и Мельчук 1980: 201-202), В.А. Плунгяна, Е.В. Рахилиной (Плунгян, Рахилина 1996: 341).

8 Функции стереотипов описываются в ключе этнолингвистики в работах О.В. Беловой (Белова 2005).

Славистика XXII/2 (2018) 
меньшей степенью фиксированности элементов. В этом русле представляет интерес рассмотрение двух вопросов: (а) каким образом стереотипные признаки слов влияют на их комбинаторику ${ }^{9}$, т.е. какова природа устойчивости смысла и формы в словосочетаниях и фраземах и (б) каковы условия, необходимые для сохранения или же нарушения этой устойчивости.

\section{Использованная литература}

Апресян, Юрий Д. Избранные труды: том I. Лексическая семантика: синонимические средства языка; том II. Интегральное описание языка и системная лексикография. Москва: Школа «Языки русской культуры», 1995.

Арутюнова, Нина Д. «Метафора и дискурс». [В:] Арутюнова, Нина Д. (ред.), Журинская, Марина А. (ред.) Теория метафоры. Москва: Прогресс, 1990, 5-32.

Арутюнова, Нина Д. Предложение и его смысл: логико-семантические проблемы. Москва: Эдиториал УРСС, 2005.

Баранов, Анатолий Н., Караулов, Юрий Н. Словарь русских политических метафор. Москва: Помовский и партнёры, 1994.

Бартминьский, Ежи. Языковой образ мира: очерки по этнолингвистике. Москва: Индрик, 2005.

Бартминьский, Ежи. «Базовые стереотипы и их профилирование на материале польского языка». [В:] Фёдорова, Людмила Л. (ред.) Стереотипы в языке, коммуникации и культуре: сборник статей. Москва: Российский государственный гуманитарный университет, 2009, 11-21.

Белова, Ольга В. Этнокультурные стереотипы в славянской народной традиции. Москва: Индрик, 2005.

Зализняк, Анна А., Левонтина, Ирина Б., Шмелев, Алексей Д. Ключевые идеи русской языковой картины мира. Москва: Языки славянской культуры, 2005.

Иорданская, Людмила Н., Мельчук, Игорь А. «Коннотация в лингвистической семантике». Wiener Slawistischer Almanach 6, 1980: 191-210.

Михалёва, Ольга Л. Политический дискурс: специфика манипулятивного воздействия. Москва: Либроком, 2008.

Плунгян, Владимир А., Рахилина, Екатерина В. «С чисто русской аккуратностью...» к вопросу об отражении некоторых стереотипов в языке». Московский лингвистический журнал 2, 1996: 340-351.

Чернявская, Валерия Е. Дискурс власти и власть дискурса: проблемы речевого воздействия. Москва: Флинта, Наука, 2006.

Чудинов, Анатолий П. Политическая лингвистика. Москва: Флинта, Наука, 2008.

Чудинов, Анатолий П. Россия в метафорическом зеркале: когнитивное исследование политической метафоры. Екатеринбург: Уральский государственный педагогический университет, 2001.

Шейгал, Елена И. Семиотика политического дискурса. Волгоград: Перемена, 2000.

Amossy, Ruth, Herschberg Pierrot, Anne. Stéréotypes et clichés : langue, discours, société. Paris: Armand Colin, 1997.

Anscombre, Jean-Claude. «Le rôle du lexique dans la théorie des stéréotypes».

${ }^{9}$ В лексикологии поддерживается тезис о том, что пословично-поговорочный фонд языка является зеркалом ментальных стереотипов (« stéréotypes de pensée »)(Schapira 2014: 71). 
Langages vol. 35, 142, 2001: 57-76.

Beliakov, Vladimir. «Le sens lexical et les croyances communautaires : interprétations référentielle et qualificative». [In:] Beliakov, Vladimir (dir.) La société russe à travers les faits de langue et les discours. Dijon: Éditions universitaires de Dijon, 2009, 39-46.

Beliakov, Vladimir. Les stéréotypes linguistiques en russe: sémantique et combinatoire. Dijon: Éditions Universitaires de Dijon, 2012.

Beliakov, Vladimir (dir.), Mejri, Salah (dir.) Stéréotypie et figement : à l'origine du sens. Toulouse: Presses universitaires du midi, 2015.

Boyer, Henri (dir.) Stéréotypage, stéréotypes : fonctionnements ordinaires et mises en scène, vol. 4, Langue(s), discours. Paris: L'Harmattan, 2007.

Charaudeau, Patrick. Le discours politique : les masques du pouvoir. Limoges: Lambert-Lucas, 2014.

Fournier Nguyen, Phi Nga. «Stéréotypie et analyse de discours». [In:] Fournier Nguyen, Phi Nga (dir.) Stéréotypie et Prototypie dans les méthodes de FLE. Atelier national de reproductions des thèses ANRT, 2 volumes. Rouen: Université de Rouen, 2005, 40-55.

Fradin, Bernard. «Anaphorisation et stéréotypes nominaux». Lingua 64, 1984: 325-369. Lippmann, Walter. Public opinion. New York: The Macmillan Company, 1947.

Magri-Mourgues, Véronique. «Construction du stéréotype et modalisation». [In:] Iliescu, Maria (éd.), Siller-Runggaldier, Heidi M. (éd.), Danler, Paul (éd.) Actes du XXVe Congrès International de Linguistique et de Philologie Romanes, 3-8 septembre 2007, Innsbruck, t. V, 153-162.

Putnam, Hilary. Signification, références et stéréotype. Philosophie 5, 1985: 21-44.

Schapira, Charlotte. «Les stéréotypes : stéréotypes de pensée et stéréotypes de langue». [In:] 4e Congrès Mondial de Linguistique Française, SHS Web of Conferences, vol. 8, 2014, 65-83.

Јулија Јурченко

\section{ПРОУЧАВАњЕ ЈЕЗИЧКИХ СТЕРЕОТИПА НА МАТЕРИЈАЛУ САВРЕМЕНОГ РУСКОГ ПОЛИТИЧКОГ ДИСКУРСА}

\section{Резиме}

У раду су сагледани поједини истраживачки поступци везани за разматрање природе стереотипа. Након теоријско-методолошких разматрања, спроведена је анализа садржаја јединица језичког израза, семантички аспекти, као и низ питања која се тичу спојивости. На материјалу савременог руског политичког дискурса показане су одлике међусобне повезаности речи у оквиру синтагми које зависе од семантичких обележја конкретних јединица. Такође, размотрена је проблематика преноса значења и улоге стереотипа приликом настанка метафора. Анализиране су стереотипне одлике речи у оквиру политичког дискурca, њихове могућности и улога у комуникацији. У закључку су представљене перспективе даљих истраживања стереотипа у области језика политике.

Кључне речи: семантика, стереотип, конотација, репродукција, комбинаторика, метафора, политички дискурс, епистемичка модалност. 